UDC 616-006.04-085.831

\title{
Nanoparticles-based photosensitizers with effect of aggregation-induced emission
}

\author{
O. V. Korneev ${ }^{1}$, T. V. Sakhno ${ }^{2}$, I. V. Korotkova ${ }^{2}$
}

${ }^{1}$ Higher Medical Educational Institution of Ukraine "Ukrainian Medical Stomatological Academy"

23, Shevchenko Str., Poltava, Ukraine, 36023

2 Poltava State Agrarian Academy

1/3, Skovoroda Str., Poltava, Ukraine, 36000

2irinakorotkova10@gmail.com

Photodynamic therapy (PDT) is a method of the treatment of localized cancers, based on a photochemical reaction between a light-activated molecule or photosensitizer (PS), light, and molecular oxygen. Correct choice of PS is of fundamental importance for PDT efficacy. Despite numerous studies in this field, most known PS have some drawbacks, e.g. lack of specificity and aggregation in aqueous media. Consequently, the search for an ideal PS is essential for further development of PDT. Here we review classification and analyse main features of different generations of PS and describe the mechanisms of their action. Various methods of targeted delivery of PS to tumor cells are discussed. The advantages of PS nanoparticles with the effect of aggregation-induced emission (AIE) over the classic photosensitizers are presented. A possibility of practical application of such light-emitting structures in cancer phototherapy is shown.

Ke y w or d s: photodynamic therapy (PDT), photosensitizer, aggregation-induced emission

\section{ABBREVIATIONS}

AEMA - 2-aminoethyl methacrylate

ALA - 5-aminolevulinic acid

AlPc - aluminum-phthalocyanine chloride

AlPcS4 - aluminium-phthalocyanine tetrasulphonated (Photosens)

AlS2Pc - disulfonated phthalocyanine

BDP - borondipyrromethene

BHQ3 - black hole quencher3

BSA - bovine serum albumin

c(RGDfc) - Arg-Gly-Asp-d-Phe-Cys cyclicpeptide

cRGD - cyclic arginine-glycine-aspartic acid

DCF-DA - dichlorofluoresceindiacetate
DMSO - Dimethylsulfoxide

DPBA-TPE - (3,3'-(2,5-dimethoxy-1,4-phenylene)bis(2-(4bromophenyl)acrylonitrile)-tetraphenylethene

DSPE-PEG-Mal — 1,2-distearoyl-sn-glycero3-phosphoethanolamine-N-[maleimide(polyethylene glycol)]

DTPEBBTD - Donor-tetraphenylethene- benzo[1,2-c:4,5-c'] $\operatorname{bis}([1,2,5]$ thiadiazole $)$

FR/NIR - far-red/ near-infrared

GFLG - Gly-Phe-Leu-Gly-peptide

HPMA - N-(2-hydroxypropyl)methacrylamide

m-THPP — meta-tetra(hydroxyphenyl)porphyrin (Foscan)

PEG - polyethyleneglycol

(C) 2019 O. V. Korneev et al.; Published by the Institute of Molecular Biology and Genetics, NAS of Ukraine on behalf of Biopolymers and Cell. This is an Open Access article distributed under the terms of the Creative Commons Attribution License (http://creativecommons.org/licenses/by/4.0/), which permits unrestricted reuse, distribution, and reproduction in any medium, provided the original work is properly cited 
PLGA - poly(lactic-co-glycolic acid)

PLGVR — Pro-Leu-Gly-Val-Arg-peptide

PpIX - protoporphyrin IX

PVM/MA - poly(methylvinyl ether-co-maleic anhydride

ROS - reactive oxygen species

TICT - Twisted Intramolecular Charge Transfer state

TPA FN - 2,3-bis[4-(diphenylamino)phenyl]fumaronitrile

TPE-red - 2-((4-(2,2-bis(4-methoxyphenyl)-1-phenylvinyl)

phenyl)(phenyl)methylene)malononitrile
TPE-TPA-DCM - 2-(2,6-bis $\left((E)-4-\left(\operatorname{phenyl}\left(4^{\prime}-(1,2,2-\right.\right.\right.$ triphenylvinyl)-[1,1'-biphenyl]-4-yl)amino)styryl)-4H-pyran4-ylidene)malononitrile

TPETPAFN - 2,3-bis(4-(phenyl(4-(1,2,2-triphenylvinyl)phenyl) amino)phenyl)fumaronitrile

TPPS4 - 5,10,15,20-tetrakis(4-sulfanatophenyl)-21H,23H-porphyrin

TTD - (2-(2,6-bis((E)-4-(phenyl(4'-(1,2,2-triphenylvinyl)-[1,1'biphenyl]-4-yl)amino)styryl)-4H-pyran-4-ylidene)malononitrile UCNPs - upconversion nanoparticles

\section{Introduction}

Photodynamic effect is dated back to 1900 and associated with $\mathrm{O}$. Raab, who obtained experimental results in the laboratory of $\mathrm{H}$. Von Tappeiner at the University of Munich. The essence of this phenomenon is that Paramecia cells (cilius infusoria) stained by acridine or other fluorescent dyes, such as quinine, methyl phosphine and eosin, in the presence of oxygen and visible light stopped moving and died [1]. The first clinical application of PDT was described by von Tappeiner and Jesionek in 1903, who applied eosin to basal cell carcinomas prior to illumination [2]. Later on, Von Tappeiner and Jodlbauer defined PDT as the dynamic interaction between light, a photosensitizing agent, and oxygen resulting in tissue destruction [3]. It took another 70 years, however, before the possibilities of PDT for the treatment of cancer became actually recognized.

In 1975, T. Doughertyet et al. reported that the hematoporphyrin derivative $(\mathrm{HpD}$, Photofrin I) in combination with red light (more than $632 \mathrm{~nm}$ ) could completely eradicate the mouse mammary tumor and Walker-256 carcinoma in rats [4]. Clinical trials with $\mathrm{HpD}$ were subsequently carried out to treat patients with bladder cancer and skin tumors. In the first studies a tube light source with a filter system was used, and in 1980 the laser radiation with a wavelength of $630 \mathrm{~nm}$ was successfully applied. A few years later, T. Dougherty with colleagues isolated an active fraction of hematoporphyrin "Photofrin II", which differed from "Photofrin I" not only by an increased selectivity of accumulation in tumors but also by more pronounced antitumor effect [5]. These drugs, like their analogues, are the first-generation PS and, along with high therapeutic activity, have a number of significant drawbacks, and above all, generalized phototoxicity.

In 1990, J. Kennedy et al proposed a fundamentally different approach to PDT, based on the use of endogenous mechanisms of inducing photosensitivity [6]. The idea was based on creation of such conditions in the human organism which would produce a synthesis of an excessive amount of endogenous porphyrins in tumor tissues capable of active generation of singlet oxygen. For this purpose, d-aminolevulinic acid, the natural precursor of protoporphyrin IX, and sufficiently active PS with absorption maximum at $630 \mathrm{~nm}$ were used. Thus the drugs for fluorescent diagnostics and PDT of keratosis, bladder cancer and brain tumors have been developed. 
Today, PDT is an established method of the treatment of localized cancers. The representative advantage of PDT is an ability to destroy cancers without destroying normal tissue structures surrounding the tumor. Additionally, the treatment can be repeated without cumulative toxicity. PDT has a number of advantages over the traditional methods of treatment, in particular, low invasiveness, high selectivity of tumor destruction, combination of diagnosis and therapy in a single scheme, the absence of severe systemic and local complications. The antitumor effects of this type of treatment are due to a combination of direct cell photodamage, destruction of the vasculature of the tumor and initiation of the immune response. The correct choice of PS is of fundamental importance for ensuring the PDT effectiveness. Nevertheless, despite numerous studies and encouraging results obtained in anti-cancer PDT using PS, most of PS have some obvious drawbacks, such as lack of specificity and aggregation in aqueous media, which limit the PDT application in clinics. Consequently, the search for an ideal PS is an actual purpose for the further development of PDT.

The aim of this study is to summarize the literature data on the photochemical properties of PS and nanoparticles of PS (NPs) possessing the effect of aggregation-induced emission (AIE) and to consider the possibility of using this effect for application of such light-emitting structures in clinical practice.

\section{Mechanism of PDT}

Photodynamic therapy of tumors is based on photophysical and photochemical processes involving the PS molecules and described in many articles [7-9]. Most of the PS molecules have the following location of energy levels: $\mathrm{S}_{0}, \mathrm{~T}_{1 \pi \pi^{*}}, \mathrm{~S}_{1 \pi \pi^{*}}, \mathrm{~T}_{2 \mathrm{n} \pi^{*}}, \mathrm{~S}_{2 \mathrm{n} \pi^{*}}$ and are characterized by a significant fluorescence quantum yield $\left(\varphi_{\mathrm{f}}\right)$ and high resistance to photochemical action [10]. At present, the main factors influencing the relative position of energy levels and, consequently, the fluorescence intensity, emission wavelengths and other fluorescence parameters are established for many heteroaromatic molecules [11, 12].

Based on the knowledge of the electronic structure of the PS molecule, it is possible to consider the mechanisms of their action. The photophysical processes, which occur at absorbed and emitted of light by PS molecules, can be represented by the scheme (Fig. 1).

To obtain a therapeutic photodynamic effect, the molecules of PS must undergo to its excited triplet state as a result of intersystem crossing (ISC $\mathrm{S}_{1} * \rightarrow \mathrm{T}_{1} *$ ). Additionally, PS can react with different surrounding molecules, generating radicals - (type I photoreaction), as well as catalyze the conversion of triplet oxygen $\left({ }^{3} \mathrm{O}_{2}\right)$ into the active excited singlet state by the triplet-triplet energy transfer mechanism $\left({ }^{1} \mathrm{O}_{2}\right)$ - (type II photoreaction) [14]. The PS* in active form directly interacts with the substrate molecules of the $\mathrm{RH}$ cell to form two radicals. The first radical is the hydrogenated form of the sensitizer oxidized by atmospheric oxygen to the original structure of PS. Another radical - the radical of the substrate - can oxidize other substrates or, at oxygen addition, form peroxide radical. The type II oxidative reactions are carried out by singlet oxygen, which is the most destructive species generated in the PDT process $[15,16]$. Exactly, singlet oxygen generated by the photochemical reaction can directly kill tumor 


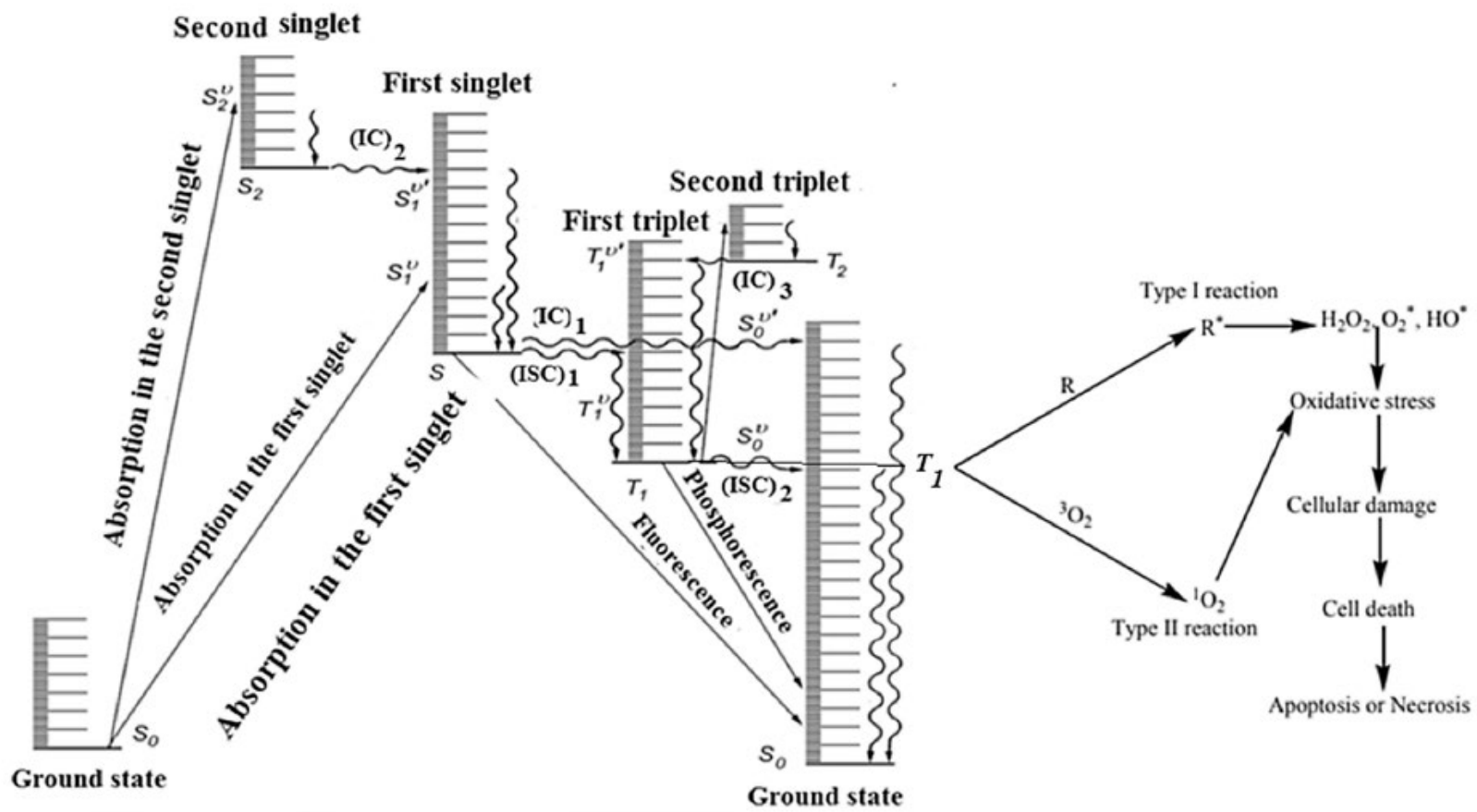

Fig.1.Modifed Jablonski diagram. Photophysical processes involved in PDT: 1) absorption, 2) fluorescence, 3) internal conversion (IC), 4) intersystem crossing (ISC), 5) phosphorescence, 6) formation of free radicals from $\mathrm{T}_{1}$ PS, and 7) formation of singlet oxygen $\left({ }^{1} \mathrm{O}_{2}\right)$ from triplet oxygen $\left({ }^{3} \mathrm{O}_{2}\right)[13]$.

cells and damage the vasculature of the tumor. The cell targets susceptible to reaction with singlet oxygen include unsaturated lipids, cholesterol, $\alpha$-amino acids (tryptophan) and nucleic acids (guanine) [17].

Currently, several new ideas are proposed regarding the mechanism of photosensitized generation of excited oxygen in the singlet state, which facilitates the targeted selection of sensitizers for photodynamic cancer therapy $[18,19]$. These mechanisms of activation of singlet oxygen involve energy transfer, which depends on exchange interactions, SOC, charge transfer, intra- and intermolecular vibrations $[20,21]$.

Thus, under the influence of the energy of light radiation in the cells of microbes or tis- sues which captured the sensitizer, a photochemical reaction occurs with the generation of singlet oxygen and free radicals - highly active biological oxidants, cytotoxic for most biological species, which leads to the death and destruction of tumor cells, microorganisms, etc.

The effectiveness of PDT in the treatment of cancer depends on the type of PS, its concentration, intracellular localization, the excitation wavelength of PS and availability of oxygen. Singlet oxygen generated by the photochemical reaction considerably more efficiently oxidizes the internal elements of cells, which leads to the destruction of internal membranes and can directly kill tumor cells by the induction of apoptosis and necrosis [22]. It also 
damages the vasculature of the tumor and surrounding healthy vessels, resulting in indirect tumor kill via the induction of hypoxia and starvation. Moreover, PDT is able to initiate an immune response against the remaining tumor cells. The mechanisms and treatment regimen can make a certain contribution to the outcome of PDT [23].

\section{Photosensitizers}

Photosensitizers are the light-adsorbing molecules, which induce chemical reactions impossible in their absence [24, 25]. By selecting PS with corresponding wavelength, it is possible to regulate the ability of light to penetrate into biological tissues. After the tumor irradiating, the photophysical and photochemical reactions develop in the tumor sites containing PS, which finally leads to the death of cancer cells. The fluorescence intensity of PS can be a ground for assessment of the tumor size and localization. Thus, the success of PDT depends on the correctly selected PS. Now, the main criteria for PS used in PDT have been established:

- absorption spectrum of PS should range from 650 to $850 \mathrm{~nm}$. In this range called the "phototherapeutic window" light penetration into tissue is maximal.

- high photochemical activity of PS characterized by the maximum yield of toxic metabolites of oxygen;

- high affinity and selectivity of accumulation in pathological target-cells with minimal amount in surrounding healthy tissues;

- absence of phototoxicity of degradation products.

The main characteristics of various generations of PS are presented in the study [26, 27].
A lot of the porphyrin derivatives (hematoporphyrin and its derivative $(\mathrm{HpD})$ were investigated as the first-generation photosensitizers for PDT [28, 29]. In 1993 the purified fraction of the active material in $\mathrm{HpD}$, porfimer sodium $\left(\lambda_{\mathrm{abs}}=630 \mathrm{~nm}\right)$, became the first PS to be approved for PDT. However, porphyrin's PS have some disadvantages, such as light absorption at relatively short wavelengths, low extinction coefficients and prolonged induction of skin photosensitization (1-2 months).

The second-generation photosensitizers include porphyrins (m-THPP and TPPS4) and related compounds: porphycenes, chlorins, phthalocyanines (Pc4, $\lambda_{\text {abs }}=670-700 \mathrm{~nm}$ ); AlPcS4 $\left(\lambda_{\text {abs }}=676 \mathrm{~nm}\right)$; AlS2Pc $\left(\lambda_{\text {ex }}=650\right.$ $670 \mathrm{~nm})$, ALA etc. [23]. They are activated by light of longer wavelengths $(650-800 \mathrm{~nm})$, which penetrated deeper and more selectively accumulated in the tumor tissue. However, most of second-generation PS exhibit high hydrophobicity, which limits their clinical effectiveness and leads to decreasing photodynamic activity or pharmacokinetic problems. The reason of a decrease in activity is the aggregation of molecules, which results in poor distribution in the tissue, preventing intravenous use.

Currently, the numerous PS absorbing in a longer wavelength visible and NIR spectral regions (metal complexes of porphyrins, phthalocyanines, etc.), and thereby contributing to the effective destruction of deep-lying tumors were created: tin ethyl etiopurpurin, mono-Laspartylchlorin e6, benzoporphyrin derivative, and lutetium texaphyrin. They have absorption bands at relatively longer wavelengths 660 , 664, 690 and $732 \mathrm{~nm}$, respectively.

A promising group of PS is 2, 3-naphthalocyanines. Their spectra show a strong batho- 
chromic shift of the long-wavelengths band into the NIR region - up to $800 \mathrm{~nm}$ and further. Therefore, they are used in therapy in combination with available diode lasers emitting in the NIR spectral region. The difficulty is in the propensity of water-soluble naphthalocyanines to aggregate in solutions greatly decreasing the quantum yield of ${ }^{1} \mathrm{O}_{2}$ generation [30]. To eliminate the possibility of aggregation of hydrophobic PSs in aqueous media, water-dispersible nanocarriers have been proposed.

The third-generation PS is a modification of the second-generation PS with biologic conjugates such as carriers, antibodies or liposomes for improvement of their physical, chemical and therapeutic properties. These compounds often actively targeted the tumor providing a higher selectivity. Most biological targets are the membranes that undergo rupture and the cells destroyed through the membranes around the mitochondria and the lysosomes. These organelles induce subsequent cellular destruction by necrosis or apoptosis [26]. An efficient PS of the third generation is the system composed of the hydrophobic photosensitizer AlPc associated with water dispersible PVM/MA NPs. This system showed improved photophysical and photochemical properties in aqueous media in comparison to free PS and are proved to be effective against cancerous cells of the murine mammary carcinoma cell lineage 4T1, human mammary adenocarcinoma cells MCF-7 and the mammary epithelial cell line MCF-10A [16].

Nanoparticles creation. An important step in PDT is pre-determined delivery of PS to the tumor targeted cells that allows increasing the selectivity of photosensitizer accumulation in the tumor. At present, the possibility of using
NPs based on organic and inorganic materials as targeted delivery systems of PS as well as for visualization of the tumor and therapy is being actively investigated [27]. Nanoparticles containing PS have several advantages over the initial photosensitizing drugs, since they allow increasing the concentration of PS in the target tissue, as well as enhancing their photodynamic activity, despite a decrease in the sensitizer activity to generate reactive oxygen species [31].

Besides, NPs can be additionally loaded with various compounds, in turn, enhancing the effect of treatment. It has been established that the use of a heterogeneous system of delivery of PS to a tumor with NPs encounters an complication as reticuloendothelial system quickly removes such particles from the bloodstream [32]. However, the coating of NPs with polymers (first of all, PEG) allows solving this problem.

Nanoparticles based on inorganic materials. Inorganic nanoparticles are being actively developed to encapsulate PS. A wide range of NIR responsive nanomaterials such as gold nanoparticles, carbon nanotubes, grapheneoxide and upconversionnanocrystals is used as a basis for theranostic applications in PDT. These nanomaterials are able to absorb light in the region outside of tissue autofluorescence, improving imaging quality. Moreover, due to large surface area, they act as a scaffold, on which PSs, targeting moieties, other diagnostic agents and other therapeutics can be assembled [33].

The systems based on metal and metal oxide NPs, for example, noble metal NPs (silver and gold) have been created. Immobilization of PS on nanocarriers allows increasing their 
bioavailability, reducing an influence on the organism as a whole, by influencing the tumor area. It is possible to achieve an increase in the quantum yield of reactive-oxygen-species (ROS) generation in the systems containing gold NPs. It is attractive to use as carriers PS of a double hybrid system containing both polymers and gold NPs [34]. According to this principle a composite PS was created, which consisted of gold NPs in a copolymer dextranpolyacrylamide matrix and chlorin e6. Nanocomposite PS in in vitro experiments with malignant cells of the MT-4 line showed photodynamic antitumor activity 2 -fold higher than that of free chlorine e6. High antitumor photodynamic activity of the nanocomposite was confirmed in experiments in vivo in mice with transfused Lewis lung carcinoma.

In [35] indocyanine green (ICG)-loaded hollow mesoporous silica NPs (ICG/HMS NPs) are described. When the ICG NPs are loaded into the HMSNPs, they are forced to aggregate and as a result, fluorescence and singlet oxygen generation of photosensitizer-loaded HMSNP becomes self-quenched (i.e. turned off) because of the fluorescence resonance energy transfer between ICG molecules. After the NPs enter the cancer cells via endocytosis, they become strongly fluorescent and phototoxic. Additionally, intracellular absorption of the ICG nanosystem in HMSNP becomes 2.75 times higher than that of free ICG, resulting in an enhanced phototherapy of cancer.

Nanoparticles based on organic materials. When creating nanoparticles based on organic materials PS can be encapsulated in such delivery agents as liposomes, micelles, and polymers. The liposomes of various structures are used as carriers for PS [36]. The latter can be encapsulated in either the aqueous phase of liposomes or their lipid bilayers, depending on the hydrophilicity [37]. For example, to improve the selectivity of photoditazine (PS based on chlorine e6 derivative) accumulation in the tumor tissue, the liposome composite of photoditazine was created [38].

A variation of the targeted transport system is the PS conjugation with oligonucleotides, proteins and other biostructures or their fragments. An example of such a transport system is presented in [39]. Nanoparticles of the folate-modified copolymer of PLGA were used to deliver pheophorbide ( $\mathrm{Pba}$ ) to the tumor. The obtained NPs of folate-PLGA-Pba increased the effect of absorption and death of human gastric cancer cells MKN28. The pronounced fluorescence of $\mathrm{Pba}$ indicated high accumulation of FA-PLGA-Pba NPs in tumor site of the MKN28 tumor muscle model.

Similar encapsulation of PSs into an amphiphilic polymer of hyaluronic acid (HA) NPs is presented by Yoon et al in [40]. The hyaluronic acid NPs were used for delivery of the hydrophobic PS, chlorin e6 (Ce6).

The chemical conjugation of aminated $5 \beta$-cholanic acid, PEG and BHQ3 to the HA backbone resulted in self-assembled HA NPs (Fig. 2). The strategy for targeting the tumor site with the HA NPs is based on the binding of HA to CD44 receptors. Ce6-loaded-HA NPs rapidly released $\mathrm{Ce} 6$ in the tumor tissue due to the degradation of the HA backbone in the presence of the hyaluronidase abundant in the cytosol of tumor cells. After 30-min incubation with Ce6-HA NPs, a fast cellular uptake and intracellular fluorescence generation of Ce6HA NPs in HT29 cells were observed along with enhancement of the fluorescence inten- 
sity. The HT29 cells treated with Ce6-HA NPs were damaged after 2 min irradiation with NIR laser, and their viability was lower than $10 \%$.

PSs based on nanoparticles with an AIE effect. Most fluorophores entering the PS are fluorescent in dilute solutions, but once the molecules are aggregated, their fluorescence decreased or quenched completely [41, 42]. This phenomenon is called the aggregationcaused quenching. Its mechanism includes the strong intermolecular $\pi-\pi$ stacking interaction between aromatic rings that are the fragments of almost all fluorophore's molecules. Once the aggregates are formed, their excited states are deactivated via non-radiative channels.

This property has been utilized in the field of PDT in many studies [35, 43]. However, the molecules of other special types in the aggregated form demonstrate an opposite effect resulting in so-called aggregation-induced emission (AIE). Here, the luminogens (called AIEgens) are non-emissive as molecules, but once the aggregates are formed, they become emissive [41]. This phenomenon was first reported in 2001 by Tang et al in [44]. In 2002 Park et al reported aggregation-induced enhanced emission (AIEE) in similar materi- als [45]. Since then, AIE and AIEE have attracted considerable attention for fundamental research and potential applications in such fields as organic light-emitting devices, biochemical probes and chemosensors. Several mechanisms have been proposed to explain the AIE and AIEE effect: Restriction of intramolecular rotations, Restriction of intramolecular vibrations and Restriction of intramolecular motions [41]. At present, new general models for interpreting the AIE processes are created.

An archetypical AIEgen is tetraphenylethene (TPE), with four phenyl rings freely connected to a central olefin structure. In a solution state, the rotation of these rings provides a non-radiative way of dissipating exciton energy and as a result, TPE has almost no fluorescence in dilute solution. However, when TPE is aggregated by, for example, the introduction of a poor solvent such as water, the rotation is physically restrained (referred to as the restriction of intramolecular motion) and, moreover, the twisted structure of this molecule hinders the $\pi-\pi$ stacking interaction. This process leads to the emergence of AIE fluorescence [41]. This property produces interesting opportunities for using TPE in PDT.

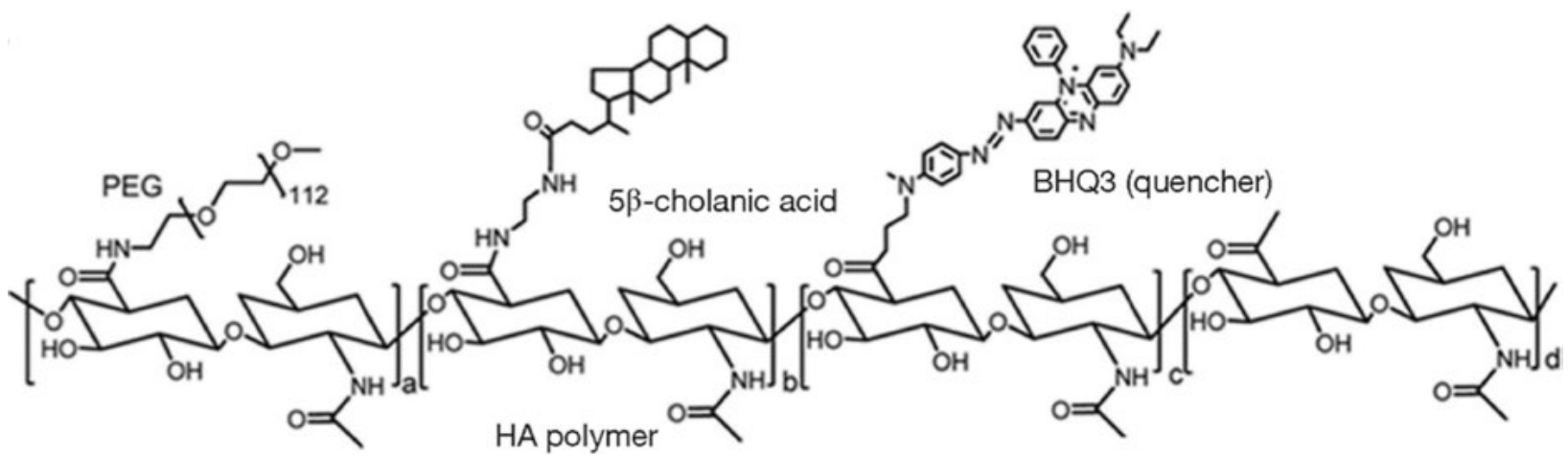

Fig. 2. Chlorin e6-loaded hyaluronic acid nanoparticles. 
The AIE effect can be used to create NPs or dots with bright fluorescence, due to the aggregation of fluorophores inside the NPs. Aditionally, it can be used to produce some kind of responses to the environment and to enable the imaging and subsequent localization of PDT (image-guided therapy).

Using a pronounced emission of AIEluminogenes in an aggregated state, AIE-dots were created. AIE-dots are very small organic nanoparticles with different functionalities demonstrating high brightness, strong photobleaching resistance and excellent biocompatibility. AIE-dots successfully used in targeted cellular and subcellular imaging, as well as in tracking cancer cells in vitro and in vivo.

TPE-TPA-DCM possessing both TICT and AIE features was synthesized. The fabricated BSA NPs show efficient FR/NIR fluorescence with low cytotoxicity [46]. When adding the TPE-TPA-DCM solution in THF to the aqueous solution of BSA, the TPE-TPA-DCM molecules aggregate and the fluorogen-loaded BSA NPs are formed instantly. The maximum emission of the fluorogen-loaded BSA NPs is located at $668 \mathrm{~nm}$. The $\varphi_{\mathrm{f}}$ values of the fluorogen-loaded BSA NPs reached $\approx 12 \%$ at a fluorogen loading of $3.07 \mathrm{wt} \%$. It was found that fluorogen-loaded BSA NPs can be successfully used for in vitro and in vivo FR/NIR bioimaging for the MCF-7 breast-cancer cells and a murine hepatoma-22 $\left(\mathrm{H}_{22}\right)$-tumor-bearing mouse model.

The ability to image the single-cell migration in real time is important in many areas of research, such as the detection of cancer metastases, cell therapy and the immunology of lymphocytes. To understand the genesis, development, invasion and metastasis of cancer- ous cells, it is required continual tracing of the biological processes by cytocompatible fluorescent probes over a long period of time. The FR/NIR fluorogen TPAFN was designed as an adduct of triphenylamine (TPA) and fumaronitrile (FN) with the AIE-effect. Then TPE was attached to TPAFN to produce TPETPAFN. The latter is an example of novel class of promising long-term cell tracing probes [47, 48]. The pure THF solution of TPAFN shows weak red fluorescence with an emission maximum at $652 \mathrm{~nm}$. With gradual addition of water to THF (water volume fractions $f_{\mathrm{w}}<70 \%$ ) the emission of TPAFN is weakened and shifted from 652 to $665 \mathrm{~nm}$. The TPAFN molecules cluster into nanoaggregates due to the poor solubility and the emission became stronger dramatically showing an obvious AIE effect when $f_{\mathrm{w}}>70$ vol. \%. Additionally, the emission maximum shifts back to $655 \mathrm{~nm}$ similar to pure THF. The emission intensity at $f_{\mathrm{w}}=90$ vol. $\%$ is 12 -fold higher than in pure THF solution. The $\varphi_{\mathrm{f}}$ of TPAFN and TPETPAFN in THF are as low as 2.32 and $0.59 \%$, whereas their $\varphi_{\mathrm{f}}$ in solid state reached 42.5 and $52.5 \%$, respectively. Further, the TPETPAFN-loaded lipid-PEG-encapsulated AIE dots were created with surface cell penetrating peptide for noninvasive in vitro and in vivo cancer cell tracing. Bioconjugation of the AIE dots with cell penetrating peptide derived from HIV-1 transactivator of transcription (Tat) protein, yielded the Tat-AIE dots with high cellular internalization efficiency. It was found that the Tat-AIE dots could trace the MCF-7 cells for 10-12 generations in vitro and the C6 cells for 21 days in vivo [47].

So far, AIE NPs (polymer NPs and silica NPs) with the blue to NIR emission have been 
successfully developed and applied in vitro and in vivo [49]. However, the currently available NIR AIE NPs have the emission spectra below $700 \mathrm{~nm}$ with the absorption maxima below $500 \mathrm{~nm}$. To obtain NIR-fuorescent AIE NPs with red/NIR absorption, the used molecules should have a narrow band gap and AIE characteristics and the emission maximum of AIE NPs in the range of $780-820 \mathrm{~nm}$.

To achieve this goal, two series of donoracceptor-donor (D-A-D) structured compounds: $a$-DTPEBBTD-C $\mathrm{C}_{\mathrm{x}}$ and $\beta$-DTPEBBTD$\mathrm{C}_{\mathrm{x}}$ were designed and synthesized (Fig.3) [50]. The monoalkoxy-substituted TPE as an electron donor formed the D-A-D structures with BBTD as an electron acceptor to produce the NIR emissive AIE molecules with desirable absorption and emission maxima for in vivo imaging applications. Noteworthy, $\beta$-DTPEBBTD- $\mathrm{C}_{\mathrm{x}}$ consists of isomers due to the geometrical difference in the positions of monoalkoxyphenyl groups, whereas $a$-DTPEBBTD- $\mathrm{C}_{\mathrm{x}}$ does not.

All compounds show higher fluorescence intensities in aggregates than in pure THF, indicative of AIE characteristics. Interestingly, the fluorescence is generally enhanced with an icrease of the alkoxy chain length. Additionally, if the polarity of environment of molecule aggregation is less than that of water, the gradual blue shifts are observed for the emission maxima when $f_{\mathrm{w}}$ changes from 50 to 90 vol.\% (from $836 \mathrm{~nm}$ to $798 \mathrm{~nm}$ for $a$-DTPEBBTD-C ${ }_{\mathrm{x}}$ and to $816 \mathrm{~nm}$ for $\beta$-DTPEBBTD- $\mathrm{C}_{\mathrm{x}}$ ). These results demonstrated that the molecules not only show AIE characteristics but also have emission maxima in the $780-820 \mathrm{~nm}$ range. The $\varphi_{f}$ of the AIE NPs gradually increased when longer substituents were used (from
$3.8 \%$ to $4.8 \%$ for $a$-DTPEBBTD- $\mathrm{C}_{\mathrm{x}}$ and from $2.2 \%$ to $3.8 \%$ for $\beta$-DTPEBBTD- $\mathrm{C}_{\mathrm{x}}$ ). The obtained NIR fluorescent $a$-DTPEBBTD-C 4 NPs have been successfully applied to the NIR fluorescence image-guided cancer surgery. They have demonstrated great potential for the accurate tumor detection with a high tumorto-normal tissue ratio of 7.2, which enabled the surgeons to perform image-guided surgery to remove tiny tumors [50].

The molecule with an AIEgen, two triphenylamine, two TPE moieties and a red-emitting TTD part in the center was used to create AIEdots. Encapsulation of TTD using DSPE-PEGMal as the encapsulation matrix, followed by the surface functionalization with the target moiety of the cRGD tripeptide was utilized to
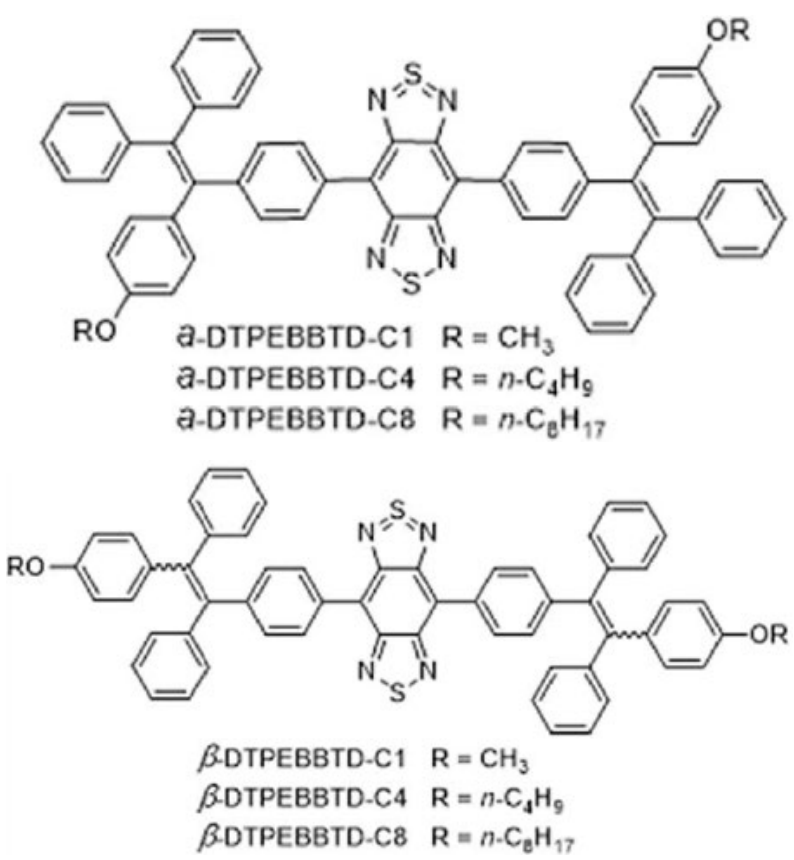

Fig. 3. Structures of D-A-D compounds: $a$-DTPEBBTD$\mathrm{C}_{\mathrm{x}}$ and $\beta$-DTPEBBTD- $\mathrm{C}_{\mathrm{x}}(\mathrm{x}-$ the number of carbon atoms of the alkoxy chain on the TPE blocks, and $\mathrm{x}$ is 1,4 or 8 ). 
prepare the targeted TTD NPs (T-TTD NPs) with a mean size of $\sim 30 \mathrm{~nm}$ (Fig. 4) [51]. The T-TTD NPs show bright red fluorescence with an emission maximum at $660 \mathrm{~nm}$. To test the targeting effect of T-TTD NPs, the MDAMB-231 cancer cells with overexpressed avb3 integrin on the cellular membrane were chosen as integrin-positive cancer cells. They were incubated and the red fluorescent signals in MDA-MB-231 cells were observed at different time points of incubation.

The ROS production by T-TTD NPs after the cancer cell uptake was evaluated using the fluorescent dye DCF-DA. The strong green fluorescence of DCF was observed inside the cells, demonstrating efficient ROS generation from the T-TTD NPs. The studies on cell viability showed that the T-TTP NPs could selectively and efficiently kill cancer cells with overexpressed $\alpha_{\mathrm{v}} \beta_{3}$ integrin.

Li et al. attached cRGD to the end of the amphiphilic PEG, targeting integrin $\alpha v \beta 3$ overexpressing cholangiocarcinoma cells (CC) [52]. The T-TTD dots were prepared by the modified nanoprecipitation method using DSPE-mPEG and DSPE-PEG2000-cRGD to form NPs with TTD molecules encapsulated as the hydrophobic core and cRGD exposed to the aqueous media. The emission spectra of
T-TTD dots have maximum at $660 \mathrm{~nm}$. The ROS quantum yield of T-TTD dots was determined to be 0.51 , which is comparable to clinically used PSs such as Photofrin $(\varphi=$ $0.28)$ or Laserphyrin $(\varphi=0.48)$ [52]. Thereby, the obtained AIE-dots showed high specificity to $\mathrm{CC}$, and also had an excellent antitumor effect both in vitro and in vivo.

The fluorescent probe systems DPBA-TPE with the AIE characteristics, which emit strong red fluorescence and can efficiently generate ROS in the state of aggregates are presented in [53]. DPBA-TPE in THF showed an absorption maximum at $480 \mathrm{~nm}$ and weak orange-red fluorescence with the emission maximum at $619 \mathrm{~nm}$. The AIE properties of DPBA-TPE were analyzed by measuring its photoluminescence spectrum changes in water/ THF mixtures with different values of $f_{\mathrm{w}}$. It was established the enhancing of DPBA-TPE emission with increasing $f_{\mathrm{w}} \approx 50 \%$. These data indicate that DPBA-TPE possesses AIE characteristics.

The ability of the DPBA-TPE system to generate ROS in aggregated state was studied also. The mixed aqueous solution of DPBATPE $\left(10 \cdot 10^{-6} \mathrm{M}\right)$ showed a quick increase in the fluorescence at $530 \mathrm{~nm}$ upon exposure to white light irradiation $\left(250 \mathrm{mWcm}^{-2}\right)$ within

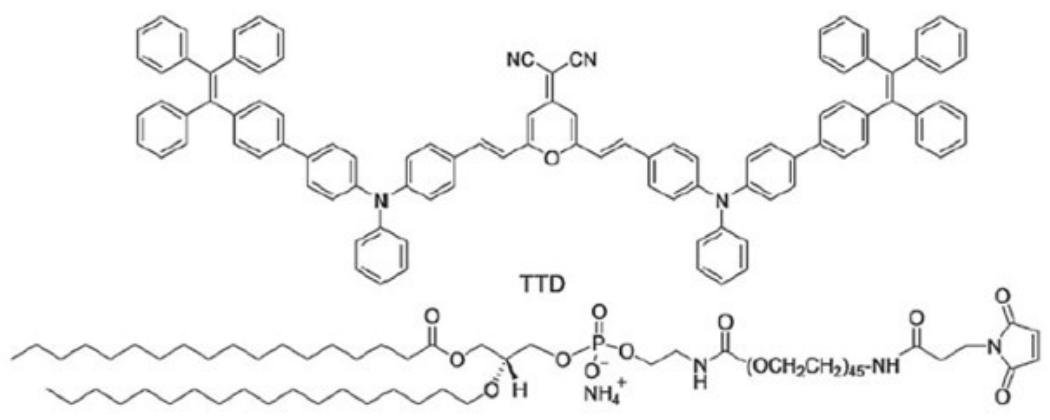

DSPE-PEG-MAL
Fig. 4. Schematic illustration of T-TTD NPs formation 
minutes, indicating the DPBA-TPE aggregates to be capable of efficient generation of the singlet oxygen species. Based on DPBA-TPE and the PEG derivatives with a folic acid (FA) fragment, the nano-sized dots with bright red fluorescence and high ROS generation were fabricated for cellular and mitochondrial dualtargeting [53]. To deliver AIE dots to mitochondria, the cationic TPP, which are able to accumulate in mitochondria in response to high mitochondrial membrane potential, reacted with the AIE dot suspension to yield FA-AIETPP dots. Folic acid promotes the cellular uptake to the folate receptor (FR)-positive cancer cells, and TPP drives AIE dots to accumulate in mitochondria. The studies on cell viability revealed the dual-functionalized FAAIE-TPP dots showed more efficient anticancer PDT effects than the single-ligand-functionalized AIE-TPP or AIE-FA dots. Thus, FA-AIE-TPP dots were yielded for specific targeting of FR-positive mitochondria of MCF-7 human breast carcinoma.

To achieve the mitochondrial targeting, various cationic lipophilic fluorescent dyes, attracted to mitochondria due to large values of the membrane potential $\left(\Delta \Psi_{\mathrm{m}}\right)$, have been developed. The $\Delta \Psi_{\mathrm{m}}$ value is a critical parameter reflecting the mitochondrial functional status and cell viability [54]. However, the photostability of these dyes is extremely low due to the effect of concentration on the emission quenching [55]. To solve this problem the potential of AIE-luminogens is widely used at present. Due to the AIE effect, the photostability of these probes improved significantly. However, most of these probes emit in a short wavelength region and do not respond to the changes of $\Delta \Psi_{\mathrm{m}}$. On the other hand, the probes emitting in a longer wavelength region offer various advantages such as minimum photodamage of biological samples, deep tissue penetration. An example of such luminogen is a mitochondrial specific AIE-luminogen, TPE$\mathrm{Ph}$-In, obtained by incorporating indole salt into the TPE [56]. TPE-Ph-In emits weakly in DMSO. The emission of TPE-Ph-In enhanced about 70 times at the formation of aggregates in the solvent mixture $\mathrm{DMSO} / \mathrm{H}_{2} \mathrm{O}$ when $f_{\mathrm{w}} \approx 99 \%$. At that condition a stronger red fluorescence at $670 \mathrm{~nm}$ was observed. Thus, TPE$\mathrm{Ph}-\mathrm{In}$ is AIE active. More importantly, the fluorescence signals of TPE-Ph-In can directly represent $\Delta \Psi_{\mathrm{m}}$ based on the positive correlation between the fluorescence intensity and the local dye concentration in mitochondria. The possibility of applying TPE-Ph-In to determine the $\Delta \Psi_{\mathrm{m}}$ change in living cells was confirmed using the membrane-potential stimulants, oligomycin and carbonyl cyanide 3-chlorophenylhydrazone. The cells were treated with the stimulants prior to the staining process, the fluorescence changes were recorded.

The using of TPE conjugated with dicyanovinyl promoted the production of high twophoton absorption cross section, thereby a promising two-photon imaging technology was established [57]. The conjugation of TPE with benzothiazole derivatives, which facilitates the self-assembly with NPs, was shown to be effective towards PC3 human prostate cancer cells, both in vitro and in vivo [54].

Mitochondria-targeting NPs were fabricated using AIE cross-linked copolymer (PAIETPP), decorating with TPP as the mitochondria-target group and possessing the segments of AIE monomer AEMA and HPMA (Fig. 5) 
[58]. The average diameter of PAIE-TPP NPs is $260 \mathrm{~nm}$. TPP can direct NPs specifically to mitochondria, and then generate ROS at specific sites, which leads to mitochondrial collapse and apoptosis of the cells. Namely, $\mathrm{pH}$-sensitive linker allowed the PEG layer to be shed once the NPs were in an acidic environment of tumor cells, after which the TPP moiety on the NPs allowed mitochondrial targeting. It is confirmed that the UCNPs, together with the AIEgen generate ROS efficiently under NIR irradiation, which allowed effective PDT against A549 human lung cancer cells. The obtained NPs with a cross-linked copolymer not only emit an enhanced FR/NIR fluorescence, but also generate highly reactive oxygen (77.9\%) [59].

The small energy gap $\left(\Delta \mathrm{E}_{\mathrm{ST}}\right)$ between the lowest singlet-excited state $\left(\mathrm{S}_{1}\right)$ and the lowest triplet-excited state $\left(T_{1}\right)$ is favorable for ISC to process efficiency ROS generation. The $\Delta \mathrm{E}_{\mathrm{ST}}$ of AIEM is around $0.277 \mathrm{eV}$, such a small $\Delta \mathrm{E}_{\mathrm{ST}}$ is expected to promote the ISC process efficiently, benefiting ROS generation [59].

TPE derivative conjugated to the peptide chain and cRGD was used to create a cathep$\sin \mathrm{B}$ sensitive probe. Cathepsin B is a lysosomal protease overexpressed in many types of tumors [60]. An activatable probe can be created by incorporating a target ligand and a substrate that can be cleaved by cathepsin B. Cathepsin B sensitive probe makes it possible to achieve highly specific cancer cell killing as a result of the dual selection processes [61]. The probe is composed of four parts: 1) an orange fluorescent AIE fluorogen as an imaging reagent and photosensitizer, 2) a GFLG peptide substrate that is responsive to cathep$\sin \mathrm{B}, 3)$ a hydrophilic linker with three Asp $\left(D_{3}\right)$ units to increase the hydrophilicity of the

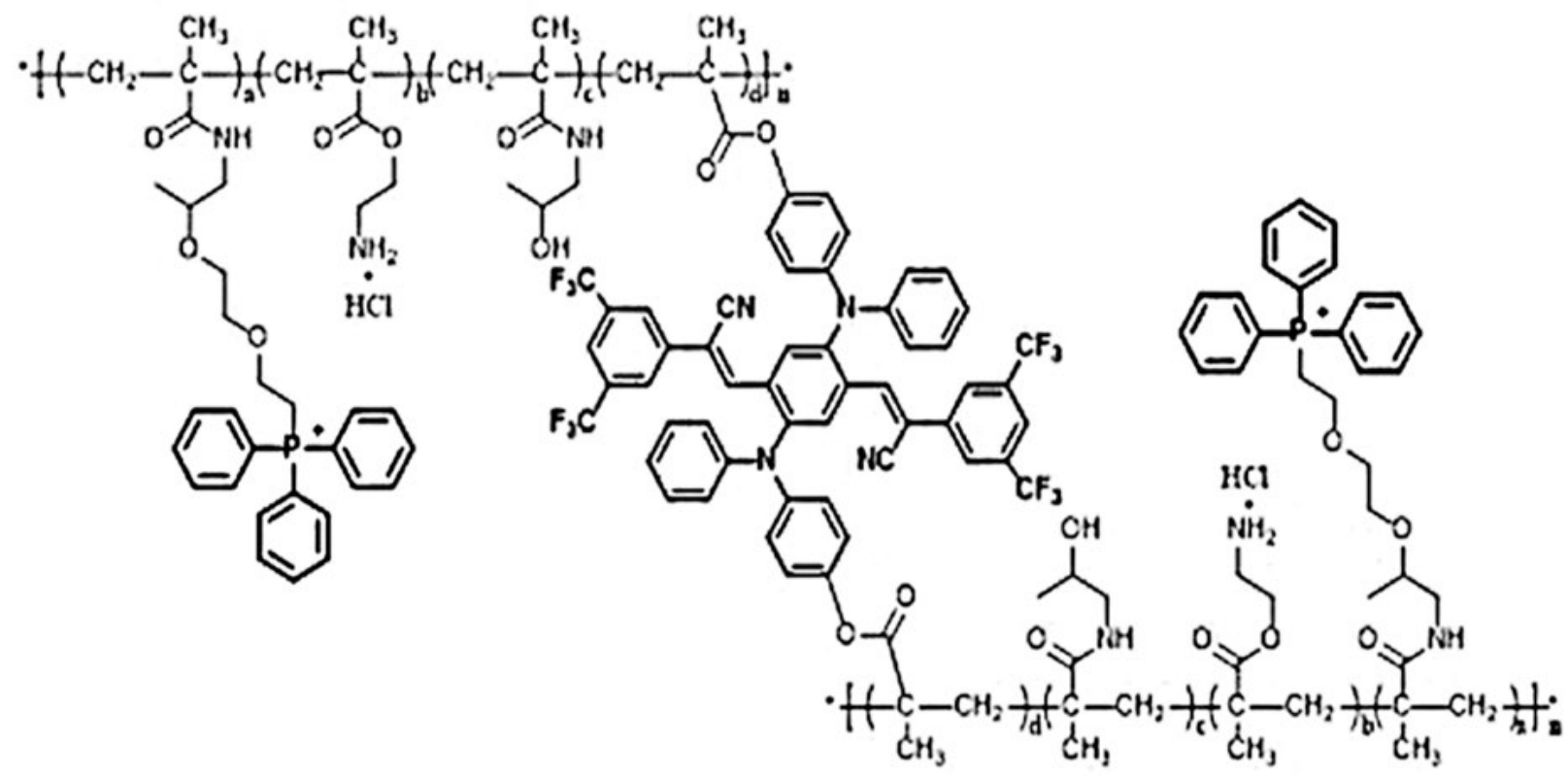

Fig. 5. Schematic illustration of the PAIE-TPP NPs as mitochondria-targeted agents 
probe, and 4) a cRGD-targeting moiety (Fig. 6).

TPE was used as AIE fluorogen. The incorporation of dicyanovinyl groups into TPE yielded to shift of emission from orange to red region. To test whether the dicyanovinyl-modified TPE derivative retained the AIE properties, the fluorescence intensity of TPECM- $2 \mathrm{~N}_{3}$ in DMSO/ $\mathrm{H}_{2} \mathrm{O}$ mixtures with different $f_{\mathrm{w}}$ was studied. TPECM-2 $\mathrm{N}_{3}$ was found to be almost non fluorescent in DMSO. However, as $f_{\mathrm{w}}$ value increased to $99 \%$, the fluorescence intensity increased by 105 times compared with DMSO. These results indicate that the dicyanovinylmodified TPE retains the AIE properties. The probe itself is almost nonfluorescent in aqueous media. After cancer-cellular uptake, a cleavage of the GFLG substrate by cathepsin B should lead to enhanced fluorescence signal output concomitant with activated photoactivity. For the presented probe, it was observed a steady increase in the fluorescence of the probe solution during 60-min incubation with cathepsin $\mathrm{B}$ in DMSO/buffer $(1: 199, \mathrm{v} / \mathrm{v})$. The increasing of fluorescence at 35-fold higher than the intrinsic emission of the probe was observed. The ag- gregate formation clearly explains the probe fluorescence turn-on in the presence of cathep$\sin \mathrm{B}$. The key role in probe properties plays its low cytotoxicity. The evaluation of the probe cytotoxicity to MDA-MB-231, MCF-7, and $293 \mathrm{~T}$ cells upon incubation for $24 \mathrm{~h}$ in the dark revealed no significant cytotoxicity for any of tested cells, even when the probe concentration reached $50 \mu \mathrm{m}$. However, upon irradiation with light, a dose-dependent cytotoxicity was observed in MDA-MB-231 cells and only minimal toxicity in MCF-7 and 293T cells. At the same time, the pretreatment of MDA-MB-231 cells with cRGD decreased cell death, which is in agreement with the apoptosis studies. Furthermore, the probe-stained MDA-MB-231 cells were exposed to irradiation with light for different durations. A stronger inhibition of cell viability was observed at a longer laser irradiation [61].

To identify solid tumor cells the biosensor TPPP was proposed, which consisted of a PS PpIX and an AIE molecular TPE with PEGylated PLGVR peptide sequence as a linker [62]. When TPPP arrives at the tumor tissue, the overexpressed MMP-2 in tumor

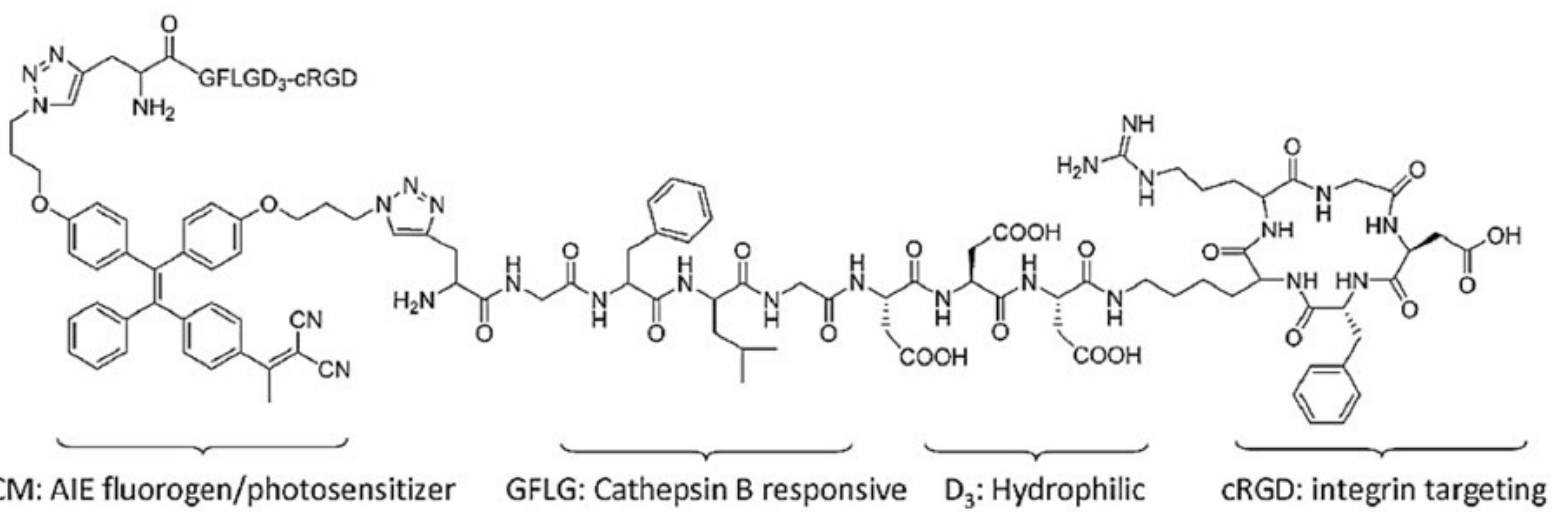

Fig. 6. Schematic illustration of bioprobe TPECM-2GFLGD3-cRGD. 
region hydrolyzed the PLGVR sequence, leading to the detachment of TPE demonstrating the AIE-effect and PEGylated PpIX.

The MMP-2 expression level can be evaluated with the ratiometric fluorescence measurement for TPE and PpIX. On the other hand, this AIE-effect provided a visible and accurate feedback of the photodynamic time and region. The efficient SCC-7 tumor accumulation of TPPP under light irradiation leads to enhanced therapeutic efficacy with reduced side effects. The intravenous injection of TPPP solution along with 20-min light irradiation inhibits the growth of tumor significantly, which proves good antitumor efficacy of TPPP under light irradiation.

Based on AIEgen TPE-red with an outstanding ability to produce ROS performs the dualfunction AIE NPs for the purposeful and visual-guided PDT in vivo targeting UMUC3 cells (human bladder cancer cell line), HeLa (human cervical cancer cell line), and A549 (human lung carcinoma cell line) [63]. To enhance tumor targeting, promote endocytosis and ensure a therapeutic effect, the NPs were modified with a customized peptide, c(RGDfc), a group commonly used to target overexpressed integrin $\alpha v \beta 3$ in most cancerous cells. TPE-red is weakly emissive in pure THF whereas the fluorescence intensity of TPE-red-PEG-RGD NPs is 9.5-times higher than that of TPE-red. The main advantage of TPE-red-PEG-RGD NPs, a high antitumor efficiency, could be achieved at a reasonably low dose; thus, the side effects could be fewer.

The efficient image-guided candidates for cancer treatment are AIE structures based on organometallic and coordination compounds. For most transition metal complexes, the pre- dominant emission process is phosphorescence, and for a number of such compounds, as complexes Re (I), Ir (III), Pt (II), Au (I), Zn (II) and $\mathrm{Cu}$ (I), the phenomenon of aggregation-induced phosphorescence emission was observed [64]. The phosphorescence intensity and quantum yield of metal complexes are enhanced by adding poor solvents like in the case of organic compounds to induce highphosphorescent nanoaggregates, which can be active components of biosensors [65]. Now only a few neutral iridium complexes with aggregation-induced phosphorescent emission have been well studied [33, 66]. For example, cyclometalated Ir(III) complexes IrBDP could self-assemble into organic nanoparticles (IrBDP NPs) and show enhanced photodynamic effect, which promotes their use for cell imaging, as well as for carrying out PDT under low energy irradiation [67]. The IrBDP complex emits with a maximum at $526 \mathrm{~nm}$, however, as a result of self-association in water the maximum emission shifted to $554 \mathrm{~nm}$. Phototoxicity of IrBDP NPs against murine colon cancer (CT26) and HeLa cell line was validated. In order to demonstrate the cell death mechanism, the cells apoptosis experiment was conducted. The experiment showed a significant increase in the apoptosis rate of CT26 cells from $12.36 \%$ to $85.1 \%$ and $\mathrm{HeLa}$ cells from $2.555 \%$ to $69.8 \%$ at treatment with IrBDP NPs upon irradiation. These results manifest that the IrBDP NPs possess an excellent photodynamic effect.

\section{Conclusions}

We demonstrated that PSs on the base of AIEluminogens can be effective tools to monitor many important biological processes at PDT. 
The application of the AIE-luminogens as PSs, which show high emission and efficient ROS production in the aggregated state, will provide a straightforward solution of the ACQ problem. Additionally, the application of AIEfluorophores emitting in the FR/NIR is beneficial due to the high penetration depth in tissue and low biological autofluorescence interference in bioimaging and PDT applications. The creation of NPs with AIE-effect based on organic or inorganic materials using physical interactions will provide targeted delivery of PS to the tumor, its visualization and subsequent localization of therapy (image-guided therapy).

In general, the development of PS with the AIE effect will expand their use in biomedical research, including visualization in vitro and in vivo of biological structures (organelles, cells, tissues etc.) as well as in the studies of cellular processes (apoptosis, metastases, etc.). The obtained results of the researches will be applied in the complex problems of the PDT which cannot be solved by traditional strategies.

\section{REFERENCES}

1. Raab $O$. Über die Wirkung fluorescieren der Stoffe auf Infusorien. Ztg Biol. 1900; 39: 524-6.

2. Von Tappeiner H, Jesionek H. Therapeutische versuche mit fluoreszierenden stoffen. Munch Med Wochenschr. 1903; 47:2042-4.

3. Von Tappeiner HA, Jodlbauer A. Die SensibilisierendeWirkung Fluorescierender Substanzen: Gesammelte Untersuchungen Über die Photodynamische Erscheinung. Leipzig, Germany: F.C.W. Vogel, 1907:p 210.

4. Dougherty TJ, Grindey GB, Fiel R, Weishaupt KR, Boyle DG. Photoradiation therapy. II. Cure of animal tumors with hematoporphyrin and light. J Natl Cancer Inst. 1975;55(1):115-21.

5. Dougherty TJ. Photodynamic therapy--new approaches. Semin Surg Oncol. 1989;5(1):6-16.
6. Kennedy JC, Marcus SL, Pottier RH. Photodynamic therapy (PDT) and photodiagnosis (PD) using endogenous photosensitization induced by 5-aminolevulinic acid (ALA): mechanisms and clinical results. J Clin Laser Med Surg. 1996;14(5):289-304.

7. Barashkov NN, Sakhno TV, Nurmukhametov RN, Khakhel'OA. Excimers of organic molecules. Russ Chem Rev. 1993; 62(6): 539-52.

8. Korotkova IV, Sakhno TV, Barashkov NN. A quantum-chemical study of the influence of changes in the geometry of nitrogen-containing heterocyclic compounds on their fluorescent characteristics. Russ J Phys Chem A. 1999; 73(1): 83-6.

9. Stennett EM, Ciuba MA, Levitus M. Photophysical processes in single molecule organic fluorescent probes. Chem Soc Rev. 2014;43(4):1057-75.

10. Plotnikov VG. Theoretical foundations of the classification of molecules by luminescence spectra. Russ Chem Rev. 1980; 49(2): 172-89.

11. Barashkov NN, Korotkova IV, Sakhno TV. Spectral manifestations of aggregates structure of heteroaromatic molecules at low temperatures. $J$ Lumin. 2000; 87-89: 794-6.

12. Korotkova IV, Sakhno TV, Barashkov NN. Theoretical study of radiationless deactivation of a series of coumarin derivatives. Theor Exp Chem. 1997; 33(2): 90-4.

13. Grynyov BV, Sakhno TV, Senchishin VG. Optically transparent and fluorescent polymers. Kharkiv Institute of single crystals $2003 ; \mathbf{5 7 5} \mathbf{~ p .}$

14. Muehlmann LA, Ma BC, Longo JP, Almeida Santos Mde F, Azevedo RB. Aluminum-phthalocyanine chloride associated to poly(methyl vinyl ether-co-maleic anhydride) nanoparticles as a new third-generation photosensitizer for anticancer photodynamic therapy. Int J Nanomedicine. 2014;9:1199-213.

15. Foote CS. Definition of type I and type II photosensitized oxidation. Photochem Photobiol. 1991;54(5):659.

16. Hamblin MR, Newman EL. On the mechanism of the tumour-localising effect in photodynamic therapy. J Photochem Photobiol B. 1994;23(1):3-8.

17. Hudson R, Boyle RW. Strategies for selective delivery of photodynamic sensitisers to biological targets. J Porphyr Phthalocyanines. 2004; 8(7): 954-75. 
18. Minaev BF, Yashchuk LB. Possible electronic mechanisms of generation and quenching of luminescence of singlet oxygen in the course of photodynamic therapy: ab initio study. Biopolym Cell. 2006; 22(3): 231-5.

19. Bregnhøj M, Westberg M, Minaev BF, Ogilby PR. Singlet oxygen photophysics in liquid solvents: converging on a unified picture. Acc Chem Res. 2017;50(8):1920-1927.

20. Minaev BF. Electronic mechanisms of molecular oxygen activation. Russ Chem Rev. 2007;76(11): 988-1010.

21. Minaev B. Photochemistry and spectroscopy of singlet oxygen in solvents. Recent advances which support the old theory. Chem Chem Tech. 2016; 10(4S): 519-30

22. Abrahamse H, Hamblin MR. New photosensitizers for photodynamic therapy. Biochem J. 2016; 473(4):347-64.

23. Triesscheijn M, Baas P, Schellens JH, Stewart FA. Photodynamic therapy in oncology. Oncologist. 2006;11(9):1034-44.

24. Allison RR, Downie GH, Cuenca R, Hu XH, Childs CJ, Sibata $\mathrm{CH}$. Photosensitizers in clinical PDT. Photodiagnosis Photodyn Ther. 2004;1(1):27-42.

25. Allison RR, Moghissi K. Photodynamic therapy (PDT): PDT mechanisms. Clin Endosc. 2013;46(1):24-9.

26. van Straten D, Mashayekhi V, de Bruijn HS, Oliveira S, Robinson DJ. Oncologic Photodynamic therapy: basic principles, current clinical status and future directions. Cancers (Basel). 2017;9(2). pii: E19.

27. Yi G, Hong SH, Son J, Yoo J, Park C, Choi Y, Koo H. Recent advances in nanoparticle carriers for photodynamic therapy. Quant Imaging Med Surg. 2018;8(4):433-443.

28. Lipson RL, Baldes EJ. The photodynamic properties of a particular hematoporphyrin derivative. Arch Dermatol. 1960;82:508-16.

29. Dougherty TJ, Kaufman JE, Goldfarb A, Weishaupt KR, Boyle D, Mittleman A. Photoradiation therapy for the treatment of malignant tumors. Cancer Res. 1978;38(8):2628-35.

30. Taratula $O$, Schumann C, Duong T, Taylor KL, Taratula $O$. Dendrimer-encapsulated naphthalocya- nine as a single agent-based theranostic nanoplatform for near-infrared fluorescence imaging and combinatorial anticancer phototherapy. Nanoscale. 2015;7(9):3888-902.

31. Allémann E, Rousseau J, Brasseur N, Kudrevich SV, Lewis $K$, van Lier JE. Photodynamic therapy of tumours with hexadecafluoro zinc phthalocynine formulated in PEG-coated poly(lactic acid) nanoparticles. Int J Cancer. 1996;66(6):821-4.

32. Moghimi SM, Hunter AC, Murray JC. Long-circulating and target-specific nanoparticles: theory to practice. Pharmacol Rev. 2001;53(2):283-318.

33. Kim H, Chung K, Lee S, Kim DH, Lee H. Near-infrared light-responsive nanomaterials for cancer theranostics. Wiley Interdiscip Rev Nanomed Nanobiotechnol. 2016;8(1):23-45.

34. Gamaleia NF, Shton IO. Gold mining for PDT: Great expectations from tiny nanoparticles. Photodiagnosis Photodyn Ther. 2015;12(2):221-31.

35. Hong SH, Kim H, Choi Y. Indocyanine green-loaded hollow mesoporous silica nanoparticles as an activatable theranostic agent. Nanotechnology. 2017;28(18):185102.

36. Chen B, Pogue BW, Hasan T. Liposomal delivery of photosensitising agents. Expert Opin Drug Deliv. 2005;2(3):477-87.

37. Hadinoto K, Sundaresan A, Cheow WS. Lipid-polymer hybrid nanoparticles as a new generation therapeutic delivery platform: a review. Eur $J$ Pharm Biopharm. 2013;85(3 Pt A):427-43.

38. Hong EJ, Choi DG, Shim MS. Targeted and effective photodynamic therapy for cancer using functionalized nanomaterials. Acta Pharm Sin B. 2016;6(4):297-307.

39. Son J, Yang SM, Yi G, Roh YJ, Park H, Park JM, Choi $M G$, Koo H. Folate-modified PLGA nanoparticles for tumor-targeted delivery of pheophorbide a in vivo. Biochem Biophys Res Commun. 2018;498(3):523-528.

40. Yoon HY, Koo H, Choi KY, Lee SJ, Kim K, Kwon IC, Leary JF, Park K, Yuk SH, Park JH, Choi K. Tumortargeting hyaluronic acid nanoparticles for photodynamic imaging and therapy. Biomaterials. 2012;33(15):3980-9.

41. Mei J, Leung NL, Kwok RT, Lam JW, Tang BZ. Aggregation-Induced Emission: Together we shine, united we soar! Chem Rev. 2015;115(21):11718-940. 
42. Granchak VM, Sakhno TV, Korotkova IV, Sakhno YuE, Kuchmy SYa. Aggregation-induced emission in organic nanoparticles: properties and applications: a review. Theoretical and Experimental Chemistry. 2018; 54(3): 147-77.

43. Hong SH, Kim H, Choi Y. Enhanced fluorescence imaging and photodynamic cancer therapy using hollow mesoporous nanocontainers. Chem Asian J. 2017;12(14):1700-1703.

44. Luo J, Xie Z, Lam JW, Cheng L, Chen H, Qiu C, Kwok $H S$, Zhan X, Liu Y, Zhu D, Tang BZ. Aggregationinduced emission of 1-methyl-1,2,3,4,5-pentaphenylsilole. Chem Commun (Camb). 2001;(18):1740-1.

45. An BK, Kwon SK, Jung SD, Park SY. Enhanced emission and its switching in fluorescent organic nanoparticles. J Am Chem Soc. 2002;124(48):14410-5.

46. Qin W, Dan D, Liu J, Yuan W, Hu Y, Liu B, Tang BZ. Biocompatible nanoparticles with aggregation-induced emission characteristics as far-red/near-infrared fluorescent bioprobes for in vitro and in vivo imaging applications. Adv Funct Mater. 2012; 22(4): 771-9.

47. Li K, Qin W, Ding D, Tomczak N, Geng J, Liu R, Liu J, Zhang X, Liu H, Liu B, Tang BZ. Photostable fluorescent organic dots with aggregation-induced emission (AIE dots) for noninvasive long-term cell tracing. Sci Rep. 2013;3:1150.

48. Ding D, Mao D, Li K, Wang X, Qin W, Liu R, Chiam DS, Tomczak N, Yang Z, Tang BZ, Kong D, Liu $B$. Precise and long-term tracking of adiposederived stem cells and their regenerative capacity via superb bright and stable organic nanodots. $A C S$ Nano. 2014;8(12):12620-31.

49. Yan L, Zhang $Y, X u B$, Tian $W$. Fluorescent nanoparticles based on AIE fluorogens for bioimaging. Nanoscale. 2016;8(5):2471-87.

50. Liu J, Chen C, Ji S, Liu Q, Ding D, Zhao D, Liu B. Long wavelength excitable near-infrared fluorescent nanoparticles with aggregation-induced emission characteristics for image-guided tumor resection. Chem Sci. 2017;8(4):2782-2789.

51. Yuan Y, Feng G, Qin W, Tang BZ, Liu B. Targeted and image-guided photodynamic cancer therapy based on organic nanoparticles with aggregationinduced emission characteristics. Chem Commun (Camb). 2014;50(63):8757-60.
52. Li M, Gao Y, Yuan Y, Wu Y, Song Z, Tang BZ, Liu B, Zheng $Q C$. One-step formulation of targeted aggregation-induced emission dots for image-guided photodynamic therapy of cholangiocarcinoma. ACS Nano. 2017;11(4):3922-3932.

53. Feng G, Qin W, Hu Q, Tang BZ, Liu B. Cellular and mitochondrial dual-targeted organic dots with aggregation-induced emission characteristics for image-guided photodynamic therapy. Adv Healthc Mater. 2015;4(17):2667-76.

54. Jayaram DT, Ramos-Romero S, Shankar BH, Garrido C, Rubio N, Sanchez-Cid L, Gómez SB, Blanco $J$, Ramaiah $D$. In vitro and in vivo demonstration of photodynamic activity and cytoplasm imaging through tpe nanoparticles. ACS Chem Biol. 2016;11(1):104-12.

55. Perry SW, Norman JP, Barbieri J, Brown EB, Gelbard HA. Mitochondrial membrane potential probes and the proton gradient: a practical usage guide. Biotechniques. 2011;50(2):98-115.

56. Zhao N, Chen S, Hong Y, Tang BZ. A red emitting mitochondria-targeted AIE probe as an indicator for membrane potential and mouse sperm activity. Chem Commun (Camb). 2015;51(71):13599-602.

57. Gu B, Wu W, Xu G, Feng G, Yin F, Chong PHJ, $Q u$ J, Yong KT, Liu B. Precise Two-photon photodynamic therapy using an efficient photosensitizer with aggregation-induced emission characteristics. Adv Mater. 2017;29(28).

58. Guan Y, Lu H, Li W, Zheng Y, Jiang Z, Zou J, Gao H. Near-infrared triggered upconversion polymeric nanoparticles based on aggregation-induced emission and mitochondria targeting for photodynamic cancer therapy. ACS Appl Mater Interfaces. 2017;9(32):26731-26739.

59. Zheng Y, Lu H, Jiang Z, Guan Y, Zou J, Wang X, Cheng $R$, Gao H. Low-power white light triggered AIE polymer nanoparticles with high ROS quantum yield for mitochondria-targeted and image-guided photodynamic therapy. J Mater Chem B. 2017; 5(31): 6277-81.

60. Decock J, Obermajer N, Vozelj S, Hendrickx W, Paridaens $R$, Kos J. Cathepsin B, cathepsin H, cathepsin $\mathrm{X}$ and cystatin $\mathrm{C}$ in sera of patients with early-stage and inflammatory breast cancer. Int $J$ Biol Markers. 2008;23(3):161-8. 
61. Yuan Y, Zhang CJ, Gao M, Zhang R, Tang BZ, Liu B. Specific light-up bioprobe with aggregation-induced emission and activatable photoactivity for the targeted and image-guided photodynamic ablation of cancer cells. Angew Chem Int Ed Engl. 2015;54(6):1780-6.

62. Han K, Wang SB, Lei Q, Zhu JY, Zhang XZ. Ratiometric Biosensor for Aggregation-induced emissionguided precise photodynamic therapy. ACS Nano. 2015;9(10):10268-77.

63. Sun X, Zebibula A, Dong X, Li G, Zhang G, Zhang D, Qian J, He S. Targeted and imaging-guided in vivo photodynamic therapy of tumors using dualfunctional, aggregation-induced emission nanoparticles. Nano Research. 2018; 11(5): 2756-70.

64. Ravotto L, Ceroni P. Aggregation-induced phosphorescence of metal complexes: from principles to applications. Coord Chem Rev. 2017; 346: 62-76.

65. Sathish V, Ramdass A, Thanasekaran P, Lu K-L. Aggregation-induced phosphorescence enhancement (AIPE) based on transition metal complexes-An overview. J. Photochem and Photobiology C: Photochemistry Reviews. 2015; 23: 25-44.

66. Alam P, Dash S, Climent C, Kaur G, Choudhury AR, Casanova D, Alemany P, Chowdhury R, Laskar IR. Aggregation-induced emission' active iridium(III) complexes with applications in mitochondrial staining. $R S C A d v$. 2017; 7: 5642-8.

67. Liu Y, Song N, Chen L, Xie Z-G. BODIPY@Ir(III) complexes assembling organic nanoparticles for enhanced photodynamic therapy. Chin J Polymer Sci. 2018; 36(3): 417-424.

\section{Фотосенсибілізатори на основі наночастин з ефектом агрегаційно-індукованої емісії}

\section{О. В. Корнеев, Т. В. Сахно, І. В. Короткова}

Фотодинамічна терапія (ФТД) — це метод лікування локалізованих видів раку, що заснований на фотохімічній реакції між активованою світлом молекулою або фотосенсибілізатором (ФС), світлом і молекулярним киснем. Вирішальне значення для забезпечення ефективності ФДТ має правильно обраний ФС. Незважаючи на численні дослідження в цьому напрямку, більшість відомих ФС мають ряд недоліків, такі як відсутність специфічності і агрегація в водних середовищах. Отже, пошук ідеального ФС - актуальне завдання для подальшого розвитку ФДТ. У цьому огляді представлено класифікацію і аналізуються основні особливості ФС різних поколінь, описано механізми їх дії. Обговорюються різні способи здійснення адресної доставки ФС до пухлинних клітин. Описано переваги наночастин ФС з ефектом агрегаційно-індукованої емісії (AIE) відносно вихідних фотосенсибілізаторів. Показана можливість використання таких світловипромінюючих структур для практичного застосування в фототерапії раку.

Кл юч о в і с л о в а: фотодинамічна терапія, фотосенсибілізатор, агрегаційно-індукована емісія.

\section{Фотосенсибилизаторы на основе наночастиц с эффектом агрегационно-индуцированной эмиссии}

О. В. Корнеев, Т. В. Сахно, И. В. Короткова

Фотодинамическая терапия (ФТД) — это метод лечения локализованных видов рака, основанный на фотохимической реакции между активируемой светом молекулой или фотосенсибилизатором (ФС), светом и молекулярным кислородом. Решающее значение для обеспечения эффективности ФДТ имеет правильно выбранный ФС. Несмотря на многочисленные исследования в этом направлении, большинство известных ФС имеют ряд недостатков, такие как отсутствие специфичности и агрегация в водных средах. Следовательно, поиск идеального ФС - актуальная задача для дальнейшего развития ФДТ. В этом обзоре представлена классификация и анализируются основные особенности ФС различных поколений, описываются механизмы их действия. Обсуждаются различные способы осуществления адресной доставки ФС к опухолевым клеткам. Описаны преимущества наночастиц ФС с эффектом агрегационно-индуцированной эмиссии (АИЭ) над исходными фотосенсибилизаторами. Показана возможность использования таких светоизлучающих структур для практического применения в фототерапии рака.

Кл ючевы е сл ов а: фотодинамическая терапия, фотосенсибилизатор, агрегационно-индуцированная эмиссия.

Received 05.01.2019 